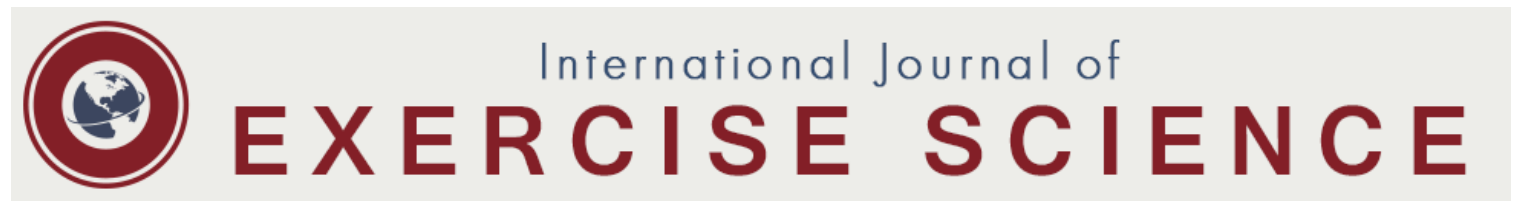

Original Research

\title{
The Effect of Acute Hyperglycemia on Muscular Strength, Power and Endurance
}

\author{
FRANKLIN LIME-MA*1, JOSHUA A. COTTER ${ }^{2}$, and EVAN E. SCHICK $¥ 2$ \\ ${ }^{1}$ Department of Health, Human Performance and Athletics, Linfield College, \\ McMinnville, OR, USA; ${ }^{2}$ Department of Kinesiology, California State University, \\ Long Beach, Long Beach, CA, USA
}

*Denotes undergraduate, $\neq$ Denotes professional author

\begin{abstract}
International Journal of Exercise Science 10(3): 390-396, 2017. The purpose of this study was to elucidate the impact of acute hyperglycemia on skeletal muscle strength, power, and endurance. Ten male collegiate athletes (age $21.5 \pm 1.5$ years, height $186 \pm 2.03 \mathrm{~cm}$, body mass $108.8 \pm 7.6 \mathrm{~kg}$ ) participated in 2 testing sessions, separated by 7 days and randomized for either high glucose (HG) or control (C) treatment conditions. HG consumed a high glucose drink (2 g glucose/ $\mathrm{kg}$ body weight) while controls consumed an isocaloric nutrition bar (40\% protein, 30\% fat, and $30 \%$ carbohydrate). Blood glucose (BC) levels for HG and C were tested at 0 (basal) and 30, 60, 90, and 120 minutes (mins) post consumption. At 30 mins post consumption, HG and C muscular strength was assessed by a 1RM bench press (BP) test followed by lower body power at 60 mins via vertical jump test. Muscular endurance was examined with a 3-set-to-failure BP test at 90 mins. HG exhibited significantly greater $B C$ values $(p<0.05)$ at the $30,60,90$, and 120 minute time points. HG glucose area under the curve was significantly greater $(p<0.05)$ than $C$ and was positively correlated with \% body fat, a finding that trended towards significance, $r=0.587, n=10$, $p=0.074$. There were no between group differences in maximal strength, power or muscular endurance. Although performance measures were unaffected by acute hyperglycemia, acute hyperglycemia can be induced and maintained in healthy, active and young subjects. Despite regular physical activity, excess body fat negatively impacts glucose metabolism.
\end{abstract}

KEY WORDS: Resistance training, diabetes, health, glycemic control

\section{INTRODUCTION}

Maintaining skeletal muscle health is critical in determining both quality and quantity of life $(2,8,11,13,15,17)$. However, insulin resistance, a consequence of conditions such as metabolic syndrome and type 2 diabetes mellitus (T2DM), is associated with metabolic dysregulation in skeletal muscle. In individuals with T2DM, insulin resistance brings about prolonged hyperglycemia, which accelerates losses in muscular strength, mass, and quality $(9,10,16)$. 
This deterioration is tied to functional reductions in isometric force, as well as inhibited dynamic strength and power (16).

Maintaining muscular competency is also crucial in non-clinical populations such as competitive athletes, who must maintain optimal muscular strength, power and endurance in order to attain peak performance. Consequently, avoiding the insults of prolonged hyperglycemia on muscle health is critical for athletes looking to maintain peak performance. Though the link between prolonged hyperglycemia and competitive athletes is weak, new evidence in high school and collegiate athletes indicates a growing prevalence of risk factors associated with metabolic syndrome including abdominal obesity and fasting hyperglycemia $(4-6,19)$. These data, while not demonstrating the existence of prolonged hyperglycemia, do raise the likelihood that collegiate athletes may experience periods of acute hyperglycemia. While significant evidence illustrates the deleterious effects of prolonged hyperglycemia on muscle, the effects of acute hyperglycemia on muscular performance are poorly understood. Therefore, the present study sought to examine the impact of acute hyperglycemia on skeletal muscle strength, power, and endurance in Division III collegiate athletes.

\section{METHODS}

\section{Participants}

Ten male collegiate Division III athletes (age $21.5 \pm 1.5$ years, height $186 \pm 2.03 \mathrm{~cm}$, body mass $108.8 \pm 7.6 \mathrm{~kg}$, \% body fat (7-site skinfold solved with Jackson Pollock equation) $22.5 \pm 3.09 \%$ ) voluntarily participated in this study. As assessed by health questionnaire, subjects were free of any cardiopulmonary and metabolic diseases. Additionally, subjects were excluded if they incurred an unresolved orthopaedic injury within 12-months of the study. All subjects signed a written informed consent and filled out a detailed health history questionnaire prior to testing. Participants had to be free of all diagnosed orthopedic, cardiovascular, respiratory and metabolic conditions. All testing procedures were approved by the Linfield College Institution Review Board.

\section{Protocol}

Subjects participated in both the high glucose (HG) and control (C) treatment conditions. Testing of the HG and C conditions took place in random order on two sessions, separated by seven days. Each session consisted of baseline measurements including body mass and a 7-site skin fold test followed by consumption of either a high glucose solution $(2 \mathrm{~g} / \mathrm{kg} B W$; Fisherbrand $100 \mathrm{~g}$ D-Glucose) or an isocaloric ( $40 \%$ protein, $30 \%$ fat, and $30 \%$ carbohydrate) nutrition bar (C). In the HG condition, subjects received a booster dose of glucose $(0.5 \mathrm{~g} / \mathrm{kg}$ BW) if concentration levels dropped $<120 \mathrm{mg} / \mathrm{dL}$. According to the American Diabetes Association (ADA), impaired glucose tolerance is present with an average glucose level of 120 $\mathrm{mg} / \mathrm{dL}$ which corresponds with Hemoglobin A1c level $>6 \%$ (1). The experimental and booster doses of glucose $(2 \mathrm{~g} / \mathrm{kg}$ BW and $0.5 \mathrm{~g} / \mathrm{kg} \mathrm{BW}$, respectively) were chosen after extensive pilot experimentation, which aimed at achieving hyperglycemia throughout the 2-hour testing session. 
Finger-prick blood collection took place at 0, 30, 60, 90, and 120 minutes (mins) postconsumption using disposable lancets (Owen Mumford Unistik 2; Marrieta, GA) and a commercially available glucometer and testing strips (OneTouch Ultra 2 and OneTouch Ultra Blue strips; Johnson \& Johnson, New Brunswick, NJ). At 30 mins, muscular strength was assessed by a 1RM bench press test (Hammer Strength, Rosemont, IL) adhering to previously established guidelines (National Strength and Conditioning Association) (7). After 60 mins, subjects performed vertical jump test (Vertec ${ }^{\circledR}$ JumpUSA, Sunnyvale, CA) to measure anaerobic power. The best of three jump attempts was recorded. At 90 mins, muscular endurance was evaluated by a three-set-to-failure bench press test with a load corresponding to $60 \%$ of their 1-repetition maximum and an intraset rest of 45 seconds. Following the muscular endurance test, subjects underwent one last blood glucose measurement at 120 mins.

\section{Statistical Analysis}

Differences in blood glucose concentrations between treatment groups was assessed by a $2 \times 5$ (Treatment [HG or C] x Time [0, 30, 60, 90, 120 mins]) repeated measures ANOVA. Student's $\mathrm{t}$-tests helped assess differences in glucose concentration at the specific time points as well as differences in area under the curve and muscular performance measures. A pearson productmoment correlation $(\mathrm{r})$ was run to correlate percent body fat $(\% \mathrm{BF})$ and glucose area under the curve (AUC). Shapiro-Wilk test confirmed normality of data (Sig $>0.05)$. All statistical analyses were performed using with SPSS version 23 (IBM, Armonk, NY) statistical software package.

\section{RESULTS}

In order to induce acute hyperglycemia in the HG condition, subjects were provided a high glucose (100g D-Glucose) solution at $2 \mathrm{~g} / \mathrm{kg}$ BW. Peak blood-glucose concentration occurred at 30 minutes post-consumption (Figure 1). The HG group exhibited significantly greater blood glucose concentrations than $C(p<0.05)$ at the 30,60, 90, and 120-minute time points (Figure 1A). Two-hour total blood glucose concentration was significantly greater $(p<0.05)$ for the HG condition as demonstrated by the area under curve (AUC) data (Figure 1B).
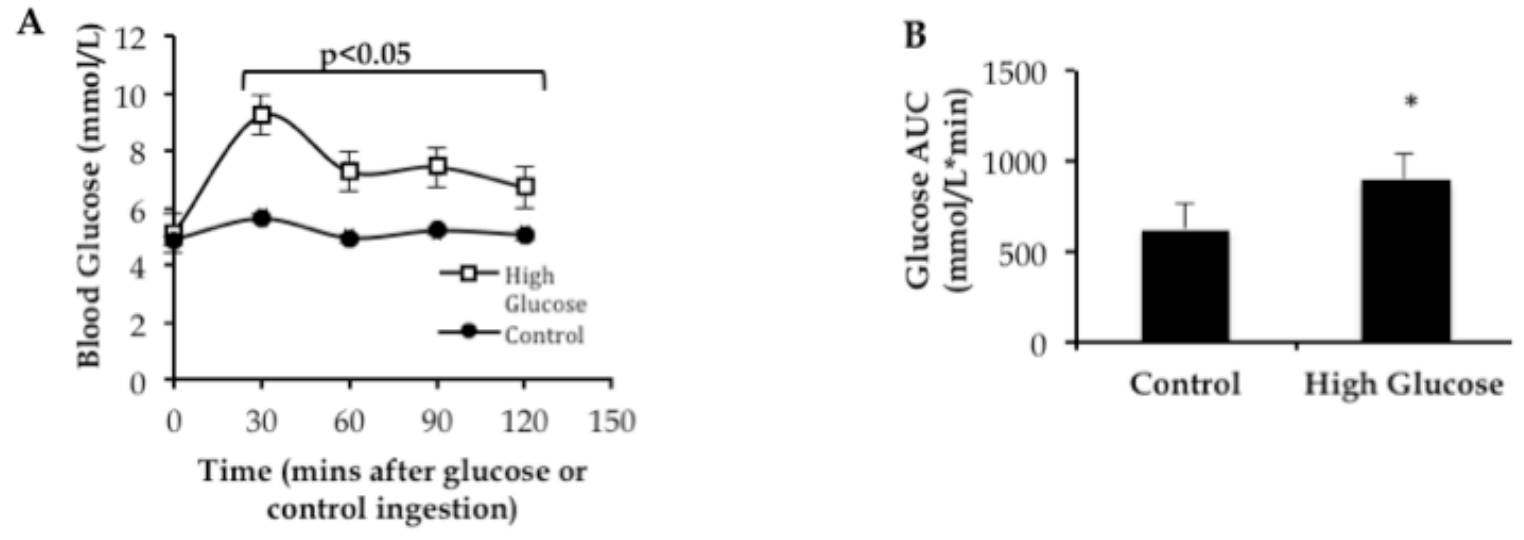

Figure 1. Whole-body glycemic response for both HG and C during performance testing over 120 minutes. A, HG displayed significantly $(\mathrm{p}<0.05)$ greater blood glucose values from $30 \mathrm{~min}$ to $120 \mathrm{~min}$ compared to $\mathrm{C}$. B, total glucose load as measured by area under the curve $(A U C)$, was significantly $(p<0.05)$ greater for HG over the 120 min time span. Values expressed as mean \pm SEM. * indicates a significant difference compared to controls. 
To gain insight into how acute bouts of hyperglycemia affect muscular performance, subjects performed: 1) a one-repetition maximum (1RM) bench press test at 30 mins post consumption, 2) a vertical jump test for lower body anaerobic power at 60 mins and 3) a 3-set-to-failure endurance bench press test at $90 \mathrm{mins}$. There were no between condition (HG vs $\mathrm{C}$ ) differences in maximal strength, power or muscular endurance (Figures 2A, B and C).
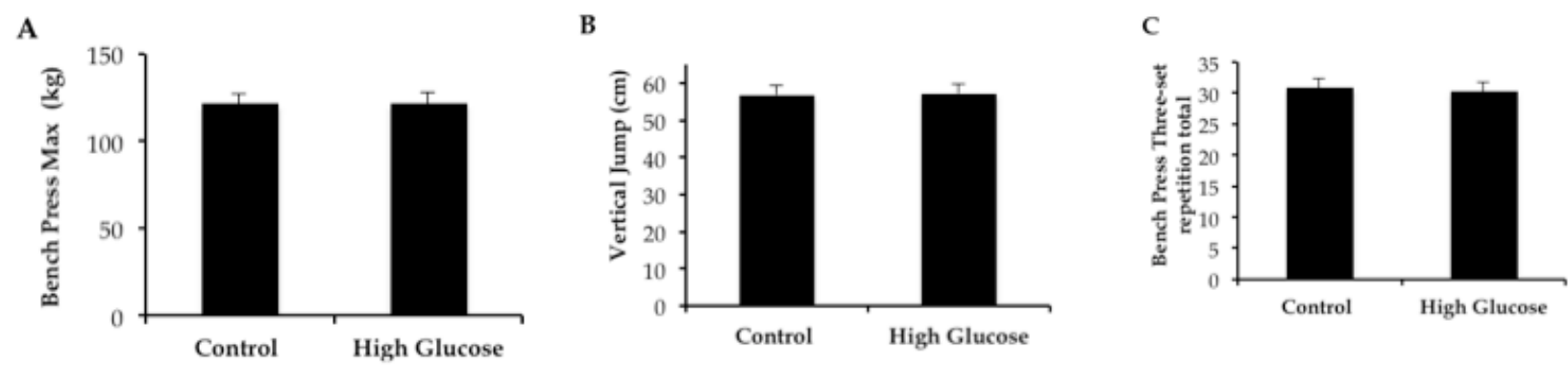

Figure 2. Muscular strength, power and endurance measures in both the HG and $C$ groups. There were no significant differences in strength (A), power (B), or endurance (C) between HG and C. Values are expressed as mean \pm SEM.

Increased body fat deposition is linked to impaired glycemic control. The present study aimed to elucidate whether this relationship is present in young athletes. A pearson product moment correlation coefficient revealed a moderate (14) positive relationship between \% body fat and two-hour total blood glucose concentration (AUC) in the HG, which trended toward significance $(\mathrm{r}=.587, \mathrm{n}=10, \mathrm{p}=0.07)$ (Figure 3$)$.

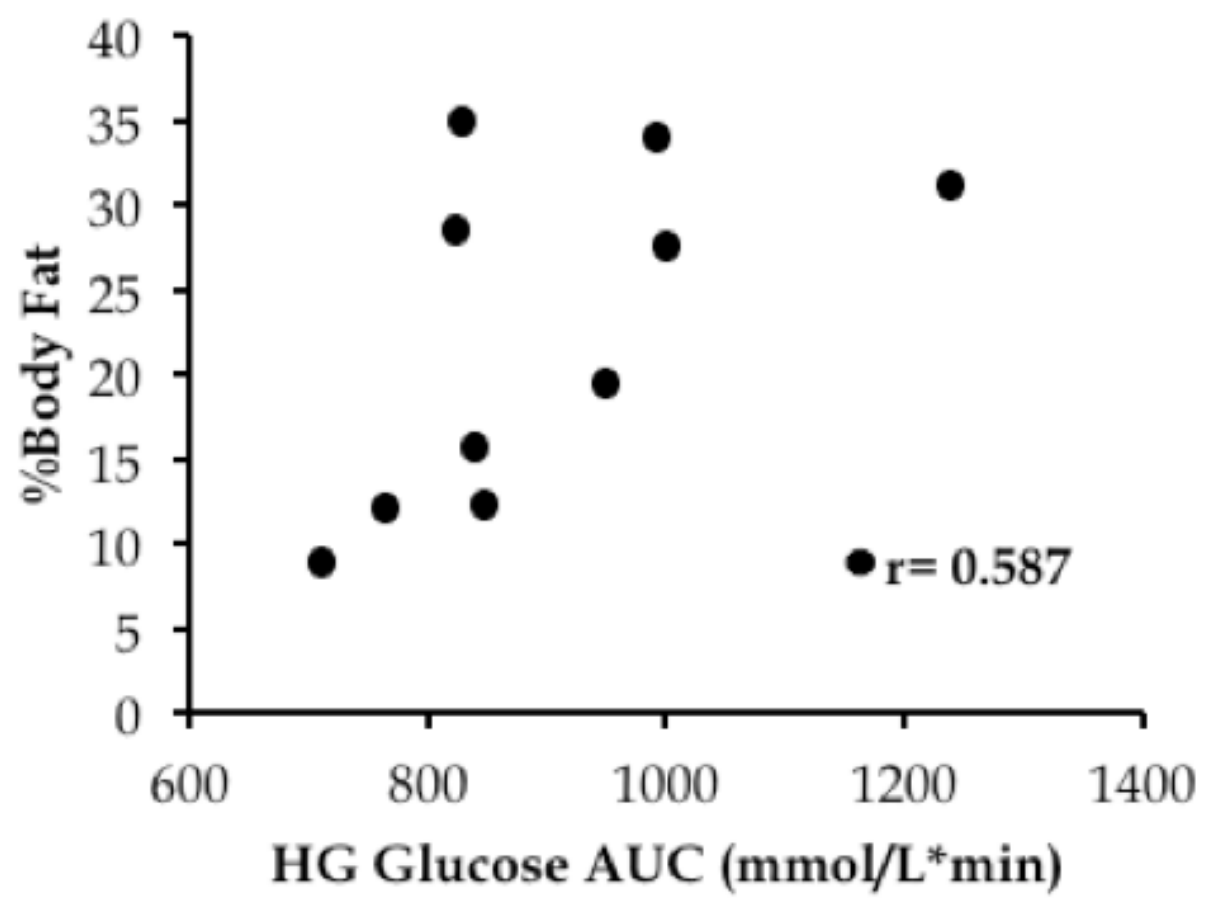

Figure 3. The relationship between total blood glucose concentration (AUC) and \% body fat (\% BF) during the 120 min glucose challenge. A Pearson product-moment correlation coefficient revealed a positive relationship between glucose HG AUC and \% BF which trended towards significance, r=0.587, n=10, p=0.074. 


\section{DISCUSSION}

We induced acute hyperglycemia in Division III collegiate athletes through oral ingestion of a D-100 glucose solution to examine whether hyperglycemia perturbs muscular strength, power and endurance in young, healthy and active individuals. The main findings were that: 1) A $2 \mathrm{~g} / \mathrm{kg}$ BW glucose feeding was adequate to induce hyperglycemia in collegiate athletes; 2 ) Hyperglycemia did not affect maximal strength, power, or muscular endurance; 3) Athletes with higher body compositions tended to exhibit reduced glucose tolerance during exercise

Chronic hyperglycemia induces many well-documented effects within skeletal muscle, which alters both the quantity and quality of life. Scarcely understood, however, is whether these effects take place in young, healthy and active individuals. In attempting to answer this question, we first set out to establish a reliable methodology of inducing acute hyperglycemia in collegiate athletes, a population within which skeletal muscle health is imperative. Although $1.5 \mathrm{~g} / \mathrm{kg}$ BW glucose solution has been previously used in diabetic populations to induce hyperglycemia during exercise (18), no such methodology currently exists for inducing hyperglycemia in otherwise healthy populations. We found that oral ingestion of a D-100 glucose solution at $2 \mathrm{~g} / \mathrm{kg}$ body weight was effective in inducing and maintaining hyperglycemia throughout exercise testing for 120 minutes. A small minority of subjects received a booster of $0.5 \mathrm{~g} / \mathrm{kg} \mathrm{BW}$ glucose solution if blood glucose concentrations dropped below $120 \mathrm{mg} / \mathrm{dL}$.

Despite previous research indicating that prolonged hyperglycemia diminishes muscular performance in clinical populations $(9,10)$, we found that acute hyperglycemia does not significantly alter muscular strength, power or endurance in an athletic population. This finding illustrates that advanced training status and youth may supersede any interference hyperglycemia might have on muscular performance. This is substantiated by others who have found that exercise may spare muscle health $(3,12,20)$.

Although the relationship between impaired glycemic control and excessive body fat is well established, the present study demonstrates the presence of this relationship even in young, active populations; in response to a glucose challenge, athletes with greater body fat percentages tended to experience greater two-hour blood glucose concentrations during exercise. These data are corroborated by recent reports, which present evidence of risk factors of metabolic syndrome in NCAA athletes $(4,19)$. Apparently, regular exercise may not be enough to balance other factors, such as genetics and/or poor diet, which may promote excessive body fat and, subsequently, alter glucose metabolism.

In summary, our findings illustrate that acute induction of hyperglycemia is attainable in young, active individuals without affecting muscular strength, power or endurance performance. We also contribute data to a growing body of evidence, which suggests that excess body fat, regardless of physical activity level or age, remains a strong indicator of impaired glucose metabolism. Indeed, coaches, trainers and nutritionists who routinely engage with youth athletes must understand that choices made while off the practice and 
playing field are crucial in influencing health. Additionally, both coaches and athletes must realize that although poor nutritional habits may not inhibit athletic performance, the competitive window is short and these habits may affect health later in life.

\section{REFERENCES}

1. American Diabetes Association. Standards of Medical Care in Diabetes-2016: Summary of Revisions. Diabetes care 39 Suppl 1:S4-S5, 2016.

2. Andersen H, Schmitz O, Nielsen S. Decreased isometric muscle strength after acute hyperglycaemia in Type 1 diabetic patients. Diabetic Med 22(10):1401-1407, 2005.

3. Boor P, Celec P, Behuliak M, Grancic P, Kebis A, Kukan M, Pronayova N, Liptaj T, Ostendorf T, Sebekova K. Regular moderate exercise reduces advanced glycation and ameliorates early diabetic nephropathy in obese Zucker rats. Metab Clin Exp 58(11):1669-1677, 2009.

4. Buell JL, Calland D, Hanks F, Johnston B, Pester B, Sweeney R, Thorne R. Presence of metabolic syndrome in football linemen. J Athl Train 43(6):608-816, 2008.

5. Chansky ME, Corbett JG, Cohen E. Hyperglycemic emergencies in athletes. Clin Sports Med 28(3):469-478, 2009.

6. Cook S, Weitzman M, Auinger P, Nguyen M, Dietz WH. Prevalence of a metabolic syndrome phenotype in adolescents: findings from the third National Health and Nutrition Examination Survey, 1988-1994. Arch Pediatr Adolesc Med 157(8):821-827, 2003.

7. Earle RW, Baechle TR. NSCA's Essentials of Personal Training. Champaign, IL: Human Kinetics; 2004.

8. Jurca R, Lamonte MJ, Church TS, Earnest CP, Fitzgerald SJ, Barlow CE, Jordan AN, Kampert JB, Blair SN. Associations of muscle strength and fitness with metabolic syndrome in men. Med Sci Sports Exerc 36(8):1301$1307,2004$.

9. Kalyani RR, Metter EJ, Egan J, Golden SH, Ferrucci L. Hyperglycemia predicts persistently lower muscle strength with aging. Diabetes Care 38(1):82-90, 2015.

10. Kalyani RR, Tra Y, Yeh HC, Egan JM, Ferrucci L, Brancati FL. Quadriceps strength, quadriceps power, and gait speed in older U.S. adults with diabetes mellitus: results from the National Health and Nutrition Examination Survey, 1999-2002. J Am Geriatr Soc 61(5):769-775, 2013.

11. Lonborg J, Vejlstrup N, Kelbaek H, Nepper-Christensen L, Jorgensen E, Helqvist S, Holmvang L, Saunamaki K, Botker HE, Kim WY, Clemmensen P, Treiman M, Engstrom T. Impact of acute hyperglycemia on myocardial infarct size, area at risk, and salvage in patients with STEMI and the association with exenatide treatment: results from a randomized study. Diabetes 63(7):2474-2485, 2014.

12. Macias-Cervantes MH, Rodriguez-Soto JM, Uribarri J, Diaz-Cisneros FJ, Cai W, Garay-Sevilla ME. Effect of an advanced glycation end product-restricted diet and exercise on metabolic parameters in adult overweight men. Nutrition 31(3):446-451, 2015. 
13. Metter EJ, Talbot LA, Schrager M, Conwit R. Skeletal muscle strength as a predictor of all-cause mortality in healthy men. J Gerontol A Biol Sci Med Sci 57(10):B359-B365, 2002.

14. Mukaka MM. Statistics corner: A guide to appropriate use of correlation coefficient in medical research. Malawi Med J 24(3):69-71, 2012.

15. Newman AB, Kupelian V, Visser M, Simonsick EM, Goodpaster BH, Kritchevsky SB, Tylavsky FA, Rubin SM, Harris TB. Strength, but not muscle mass, is associated with mortality in the health, aging and body composition study cohort. J Gerontol A Biol Sci Med Sci 61(1):72-77, 2006.

16. Park SW, Goodpaster BH, Strotmeyer ES, Kuller LH, Broudeau R, Kammerer C, de Rekeneire N, Harris TB, Schwartz AV, Tylavsky FA, Cho YW, Newman AB, Health A, Body Composition S. Accelerated loss of skeletal muscle strength in older adults with type 2 diabetes: the health, aging, and body composition study. Diabetes Care 30(6):1507-1512, 2007.

17. Reinders I, Murphy RA, Brouwer IA, Visser M, Launer L, Siggeirsdottir K, Eiriksdottir G, Gudnason V, Jonsson PV, Lang TF, Harris TB, Age GESRS. Muscle Quality and Myosteatosis: Novel Associations With Mortality Risk: The Age, Gene/Environment Susceptibility (AGES)-Reykjavik Study. Am J Epidemiol 183(1):5360, 2016.

18. Riddell M, Perkins BA. Exercise and glucose metabolism in persons with diabetes mellitus: perspectives on the role for continuous glucose monitoring. J Diabetes Sci Technol 3(4):914-923, 2009.

19. Steffes GD, Megura AE, Adams J, Claytor RP, Ward RM, Horn TS, Potteiger JA. Prevalence of metabolic syndrome risk factors in high school and NCAA division I football players. J Strength Cond Res 27(7):1749-1757, 2013.

20. Wright KJ, Thomas MM, Betik AC, Belke D, Hepple RT. Exercise training initiated in late middle age attenuates cardiac fibrosis and advanced glycation end-product accumulation in senescent rats. Exp Gerontol 50:9-18, 2014.

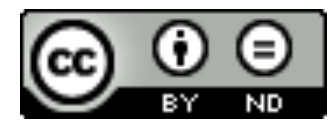

